\title{
Left atrial metastasis of chorion carcinoma, presenting as mitral stenosis
}

\author{
ALOIS HEPP, DIETER LARBIG, AND HARTMUT BADER \\ From the Cardiovascular Department, Medizinische Universitätsklinik, Tübingen, West Germany
}

A 35-year-old woman developed symptoms of multiple system disease. Three months later she was admitted to hospital and died six days after admission, with signs suggestive of mitral stenosis. Postmortem examination indicated primary chorion carcinoma of the right ovary with metastases to the left atrium, lungs, brain, kidneys, pancreas, mesenteric arteries, and spleen. The signs and symptoms, and the morphological and histological findings at necropsy, are discussed.

\section{History}

In February 1975, a 35-year-old mother of two children developed severe left-sided chest pain, headache, transient paraesthesiae, and pareses of the upper extremities, visual disturbance, agnosia, motor aphasia, and abdominal symptoms. She was admitted to our hospital three months later because of unclear pulmonary symptoms and recurrent tachycardia. The obstetric history was unremarkable.

\section{CLINICAL AND LABORATORY FINDINGS}

On clinical examination the patient was febrile and appeared chronically ill but was not in acute distress. She was slightly dyspnoeic and had a tachycardia varying between 100 and 160 beats $/ \mathrm{min}$. The cardiac findings were consistent with mitral stenosis. The blood pressure ranged between $140 / 90$ and $170 / 110 \mathrm{mmHg}$. Slight paresis of the right arm and increased right-sided tendon reflexes were noticed. Gynaecological examination revealed some tenderness of the recto-vaginal pouch but the examination was otherwise unremarkable. The electrocardiogram showed sinus tachycardia, left atrial hypertrophy, and evidence of right and left ventricular hypertrophy. The phonocardiogram showed the typical signs of mitral stenosis: accentuated first heart sound, mitral opening snap, low frequency protodiastolic murmur, and discrete presystolic murmur. The chest $x$-ray showed a typical 'mitralised configuration' of the heart, with evidence of an enlarged left atrium, filling out of the left-sided waist of the heart, a prominent pulmonary conus, and ill-defined and somewhat ir- regular margins of the hilar shadows, as well as various small patchy densities in both upper lung regions. An echocardiographic examination was not performed.

Pathological laboratory data consisted of a raised ESR of $69 / 95 \mathrm{~mm}$, a leucocytosis of $10.5 \times 10^{9} / 1$, and a pronounced anaemia with a haemoglobin of $9 \mathrm{~g} / \mathrm{dl}$.

\section{DIAGNOSIS AND COURSE}

The following diagnoses were considered: (1) bacterial endocarditis complicating mitral stenosis; (2) left-sided atrial myxoma with multiple systemic embolism; (3) collagen disorders such as systemic lupus erythematosus or polyarteritis nodosa in addition to mitral stenosis; and (4) advanced metastatic tumour disease. The patient's condition deteriorated rapidly so that it was impossible to perform further diagnostic procedures such as cardiac catheterisation and angiocardiography. Despite treatment with digitalis and diuretics pulmonary congestion increased and neurological symptoms progressed; the patient died six days after admission to hospital.

\section{PATHOLOGY AND HISTOLOGY}

A primary chorion carcinoma of the right ovary with multiple metastases was found on necropsy. Histological examination of serial sections of the uterus failed to show a tumour lesion in this organ. The most impressive finding was a metastasis in the left atrium measuring $4.0 \times 2.5 \times 3.5 \mathrm{~cm}$, which caused a high grade stenosis of the mitral orifice (Fig.), with backward extension into the pulmonary veins of the left upper lobe as far as the first branch- 


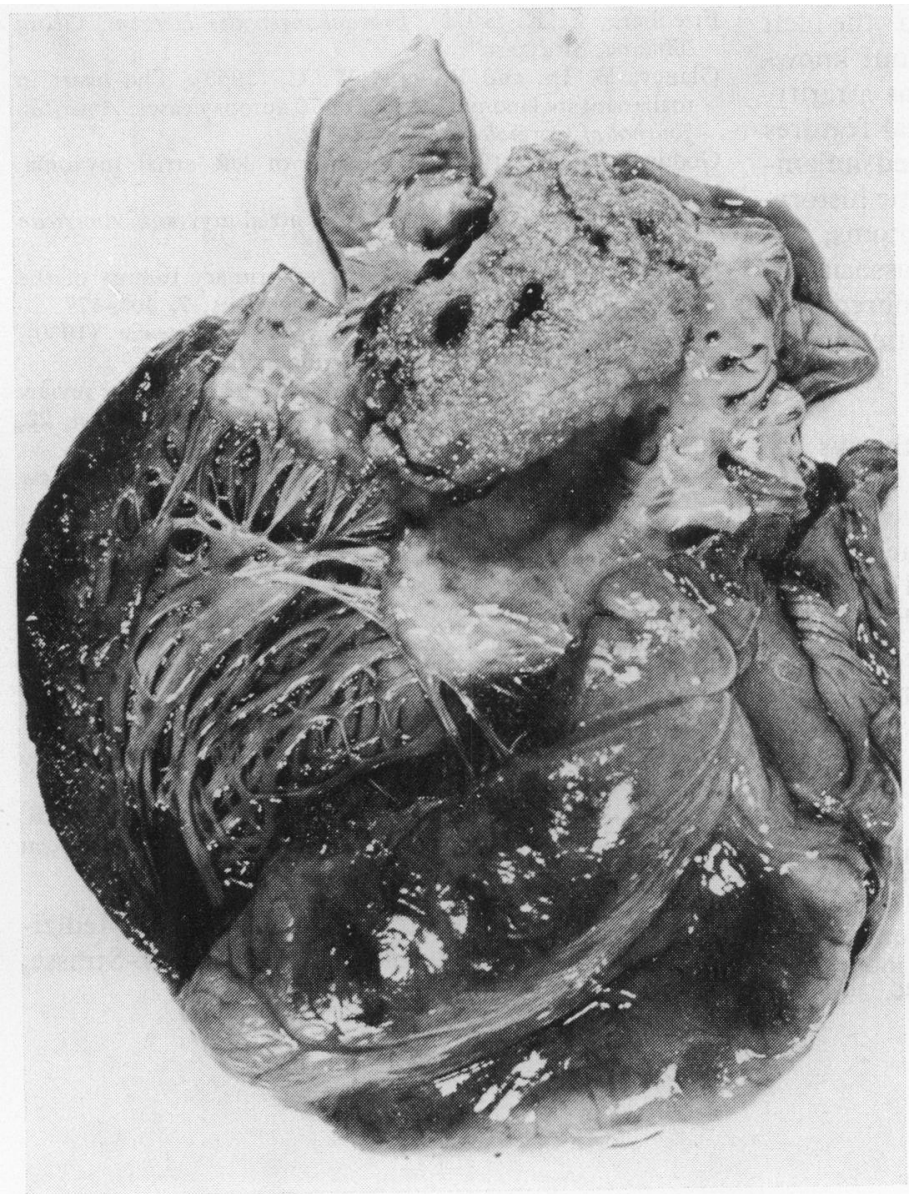

Fig. Metastatic tumour mass in the left atrium causing severe obstruction of the mitral orifice.

ing. Tumour tissue was also detected in the spleen, intestinal tract, kidneys, pancreas, brain, and pulmonary lymphatics.

\section{Comment}

Cardiac tumours are rare. In unselected necropsies primary cardiac tumours are found in 0.05 per cent, and metastatic cardiac tumours in 0.6 to $6.4 \mathrm{per}$ cent; in cases with malignant tumours, however, cardiac metastases are found in up to 21 per cent (Griffiths, 1965; Berge and Sievers, 1968; Friedberg, 1972). In principle, any metastasising tumour may also produce cardiac metastases. Carcinomata of the bronchial tree and the breast and malignant lymphoma tend to metastasise to the heart in 23 to 33 per cent (Hanfling, 1960; Roberts et al., 1968). In malignant melanoma metastases to the heart occur in up to 50 per cent of cases (Glancy and Roberts, 1968). Only 10 per cent of cardiac meta- stases cause cardiac symptoms (Hurst, 1974). Site, size, and tendency to embolism determine the clinical findings; metastases to the heart may mimic valvular disease, or produce electrocardiographic features of myocardial infarction and conduction defects (James, 1962; Conde et al., 1975). When sinus rhythm is present, multiple systemic embolism should always suggest the possibility of a cardiac tumour, particularly of left atrial myxoma (Goodwin, 1963; Greenwood, 1968). Atrial tumours presenting as mitral stenosis are most commonly myxomata, occasionally pedunculated sarcoma, and very rarely metastases (Sterns et al., 1966; Friedberg 1972).

There is a high incidence of local metastases in chorion carcinoma, and less frequently metastases are found in lungs, liver, and brain, rarely in kidneys, spleen, and heart. If the chorion carcinoma causes cardiac metastases at all, they are usually to the right side of the heart (Handbuch, 1930). 
A metastasis of chorion carcinoma to the left atrium has not been described so far to our knowledge and, therefore, must be regarded as a rarity. In the case described above the clinical features were primarily suggestive of a generalised inflammatory disease. The absence of a rheumatic history, the rapid progression of the cardiac symptoms, and the variation of the $\mathrm{A}_{2}$-OS interval in association with multiple systemic embolism favoured the diagnosis of an atrial tumour. A metastatic cardiac tumour seemed unlikely, since there was no clinical evidence of a primary tumour.

Lymphatics and veins function as pathways for the metastasising chorion carcinoma (Hanfling 1960; Rogen and Moffat, 1967). Apparently, the left atrial metastasis was initially attached to the atrial endocardium after having passed the pulmonary circulation, and extended from there backwards into the pulmonary veins. The systemic tumour emboli obviously originated from the left atrial metastasis.

\section{References}

Berge, T., and Sievers, J. (1968). Myocardial metastases. A pathological and electrocardiographic study. British Heart fournal, 30, 383-390.

Conde, C. A., Meller, J., Pantazopoulos, J., Donoso, E., and Dack, S. (1975). Reticulum-cell sarcoma with intracardiac metastases. American fournal of Cardiology, 36, 357-361.
Friedberg, C. K. (1972). Erkrankungen des Herzens. Georg Thieme, Stuttgart.

Glancy, D. L., and Roberts, W. C. (1968). The heart in malignant melanoma: a study of 70 autopsy cases. American fournal of Cardiology, 21, 555-571.

Goodwin, J. F. (1963). Diagnosis of left atrial myxoma. Lancet, 1, 464-468.

Greenwood, W. F. (1968). Profile of atrial myxoma. American fournal of Cardiology, 21, 367-375.

Griffiths, G. C. (1965). A review of primary tumors of the heart. Progress in Cardiovascular Diseases, 7, 465-479.

Handbuch der speziellen pathologischen Anatomie (1930). Vol. 7, Part I, pp. 713-801. Springer, Berlin.

Hanfling, S. M. (1960). Metastatic cancer to the heart: review of the literature and report of 127 cases. Circulation, 22, 474-483.

Hurst, J. W. (1974). The Heart, 3rd ed. McGraw-Hill, New York.

James, T. N. (1962). Metastasis of hypernephroma to atrioventricular node: report of a case. New England fournal of Medicine, 266, 705-708.

Roberts, W. C., Glancy, D. L., and DeVita, V. T., Jr. (1968). Heart in malignant lymphoma (Hodgkin's disease, lymphosarcoma, reticulum-cell sarcoma and mycosis fungoides): a study of 196 autopsy cases. American Fournal of Cardio$\log y, 22,85-107$.

Rogen, A. S., and Moffat, A. D. (1967). Unusual secondary tumour of heart. British Heart fournal, 29, 638-640.

Sterns, L. P., Eliot, R. S., Varco, R. L., and Edwards, J. E. (1966). Intracavitary cardiac neoplasms. A review of fifteen cases. British Heart fournal, 28, 75-83.

Requests for reprints to Dr. Alois Hepp, Medizinische Universitätsklinik, Otfried-Müller-Strasse, 74 Tübingen, West Germany. 